\title{
Influence of Cu-doping on the structural and optical properties of $\mathrm{CaTiO}_{3}$ powders
}

\author{
L.H. Oliveira ${ }^{a}$, A.P. de Moura ${ }^{a}$, F.A. La Porta ${ }^{\text {b** }}$, I.C. Nogueirac ${ }^{c}$, E.C. Aguiar ${ }^{\mathrm{a}}$, T. Sequinel ${ }^{\mathrm{a}}$, \\ I.L.V. Rosac ${ }^{c}$ E. Longo ${ }^{a}$, J.A. Varela ${ }^{a}$ \\ a UNESP-Universidade Estadual Paulista, P.O. Box 355, 14801-907, Araraquara, SP, Brazil \\ b Department of Chemistry, Federal Technological University of Parana (UTFPR), PO Box 3131, 86036-370, Londrina/PR, Brazil \\ ${ }^{\mathrm{c}}$ DQ-UFSCar-Universidade Federal de São Carlos, P.O. Box 676, 13565-905, São Carlos, SP, Brazil
}

\section{A R T I C L E I N F O}

\section{Article history:}

Received 20 September 2015

Received in revised form 20 April 2016

Accepted 21 April 2016

Available online 22 April 2016

\section{Keywords:}

Ceramics

Optical materials

Chemical synthesis

Microstructure

Defects

\begin{abstract}
A B S T R A C T
Here, we report on the effect of chemical substitution on the structural and optical properties of $\mathrm{Cu}$ doped $\mathrm{CaTiO}_{3}$ (CTO) polycrystalline powders synthesized by the polymeric precursor method. Our findings are discussed based on the structural order-disorder effects originating from the modification of the $\mathrm{Ca}_{1-\mathrm{x}} \mathrm{Cu}_{\mathrm{x}} \mathrm{TiO}_{3}$ microcrystal matrix. These results may elucidate the compositional modulation and methods of controlling the structural design, as well as reveal the changes in the optical behavior of this system at an atomic level.
\end{abstract}

(c) 2016 Elsevier Ltd. All rights reserved.

\section{Introduction}

Recently, complex perovskite oxides have been the subject of many studies in several fields because of their desirable properties and potential applications [1-5]. Among these promising materials, which have a general formula of $\mathrm{ABO}_{3}$, calcium titanate $\left(\mathrm{CaTiO}{ }_{3}\right.$ (CTO)) is a chemically stable, $n$-type semiconductor with a wide band-gap of $\sim 3.56 \mathrm{eV}$. CTO has excellent electrical and optical properties, which render it a potential candidate for applications such as electronic devices, computer memory, and capacitors [6,7].

Along with the development of novel complex perovskite oxide materials, a large number of synthetic strategies have recently been developed to produce CTO materials of different sizes and morphologies [8-15]. In this context, it is well known that the polymeric precursor method is a simple, clean, and efficient approach to fabricate complex functional materials. It also offers excellent chemical homogeneity and precise stoichiometric control during heat treatments at relatively low temperatures $[9,15,16]$. Hence, this synthetic strategy substantially reduces the presence of segregated phases and does not require long annealing periods compared with other synthetic methods [9,15,16].

\footnotetext{
* Corresponding author.

E-mail addresses: felipe_laporta@yahoo.com.br, felipelaporta@utfpr.edu.br (F.A. La Porta)
}

Moreover, it is well known that doping can enhance the physical and chemical properties of these materials. Hence, these chemical substitutions, especially the partial replacement of the $\mathrm{Ca}^{2+}$ or $\mathrm{Ti}^{4+}$ atoms, allow the emergence of technologically interesting properties for new applications.

From the most recent studies, up to now, the use of doped CTO materials has attracted large attention and proven to be an effective means as strategy to obtain of materials with a giant dielectric constant, new luminescent materials and so on [17-19]. As is well-known, the $\mathrm{Cu}^{2+}$ ions can influence dielectric permittivity as well as its microstructure, modifying the potential barriers, mainly when segregated into grain boundary [20-22]. From recent studies, it has been observed that a small amounts of $\mathrm{Cu}^{2+}$ ions added to CTO material (e.g., such as $2-10 \mathrm{~mol} \%$ ) is responsible for increased its dielectric permittivity in 40 times. Although permittivity values obtained for these systems being smaller than those are reported for $\mathrm{CaCu}_{3} \mathrm{Ti}_{4} \mathrm{O}_{12}$ (CCTO) perovskite, at higher concentrations of $\mathrm{Cu}^{2+}$ ions, i.e. above $40 \% \mathrm{~mol}$, a tangent of loss $(\tan \delta)$ value of approximately 0.05 at $1 \mathrm{kHz}$ was observed in the same frequency range [23]. However, it is crucial to elucidate the order-disorder effects and structural changes that occur when the $\mathrm{Ca}^{2+}$ ions in the material are replaced with $\mathrm{Cu}^{2+}$ ions. This is a key factor for the design of novel complex functional materials with tunable properties, and it is of great technological importance for many applications. 
Here, we report a detailed study on copper doping and its effects on the structural and optical properties of $\mathrm{Ca}_{1-\mathrm{x}} \mathrm{Cu}_{\mathrm{x}} \mathrm{TiO}_{3}$ powders synthesized by the polymeric precursor method. The obtained precursor was investigated using thermogravimetric analysis (TGA). These obtained powders were analyzed using X-ray diffraction (XRD) with Rietveld refinement, micro-Raman (MR) spectroscopy, field-emission scanning electron microscopy (FESEM), Brunauer-Emmett-Teller (BET) nitrogen adsorption/desorption isotherms, as well as ultraviolet-visible (UV-vis) and photoluminescence (PL) measurements. These analyses can elucidate the structural changes, which is critical for controlling the optical behavior of the $\mathrm{Ca}_{1-\mathrm{x}} \mathrm{Cu}_{\mathrm{x}} \mathrm{TiO}_{3}$ powders, being an important strategy in order to revealing its potential applications.

\section{Experimental}

The polymeric gel of $\mathrm{Ca}_{1-\mathrm{x}} \mathrm{Cu}_{\mathrm{x}} \mathrm{TiO}_{3}$ with $0 \leq x \leq 0.10 \mathrm{~mol}$ of $\mathrm{Cu}^{2+}$ ions was synthesized by polymeric precursor method. Initially, a $1.0 \times 10^{-2} \mathrm{~mol}$ solution of titanium citrate was maintained at $60^{\circ} \mathrm{C}$. Subsequently, $(1-x) \times 10^{-2} \mathrm{~mol}$ of $\mathrm{Ca}\left(\mathrm{NO}_{3}\right) \cdot 4 \mathrm{H}_{2} \mathrm{O}$ was added to the solution. Following its complete dissolution, stoichiometric quantities of $0.00,0.02,0.04$, or $0.10 \times 10^{-2} \mathrm{~mol}$ of $\mathrm{Cu}\left(\mathrm{NO}_{3}\right)_{2} .2 .5 \mathrm{H}_{2} \mathrm{O}$ were also added to the system. These samples were denoted as CTO, $x=0.02, x=0.04$, and $x=0.10$, respectively. Under constant stirring, the system was maintained at $80^{\circ} \mathrm{C}$ until its complete homogenization. Then, ethylene glycol was added to the citric acid solution in a mass ratio of 60:40, respectively; thus producing a polymeric resin. Fig. 1 shows the TGA/differential thermal analysis (DTA) curve for thermal decomposition of the polymeric resin. The TGA/DTA analysis was performed using NETZCH-STA-409CELL equipment at a heating rate of $5{ }^{\circ} \mathrm{C} / \mathrm{min}$ under an air atmosphere.

Fig. 1 presents the TGA/DTA curve for the thermal decomposition of the polymeric resin heat treated from 25 to $1000^{\circ} \mathrm{C}$. As can be seen, an exothermic peak was observed at $350{ }^{\circ} \mathrm{C}$ which is associated to a weight loss of $6.88 \%$, corresponding to decomposition of the polymer chains involving the metallic cations producing $\mathrm{CO}_{2}$ and $\mathrm{H}_{2} \mathrm{O}$, which produced an amorphous powder (see Fig. 2(ad)). Above $600^{\circ} \mathrm{C}$, none weight loss was detected, indicating that a stable ceramic oxide is formed. According to this result, crystalline $\mathrm{Ca}_{1-\mathrm{x}} \mathrm{Cu}_{\mathrm{x}} \mathrm{TiO}_{3}$ powders with $0 \leq x \leq 0.10$ of $\mathrm{Cu}^{2+}$ ions are obtained after different stages of calcination. The first step, so-called the precalcination, constitutes of the polymeric resin calcination to eliminate the larger amount of organic material, citric acid and ethylene glycol, used in the synthesis. The second step, in particular consists of a heat treating of these material for removal of residual organic materials as well as obtain a crystalline $\mathrm{Ca}_{1-\mathrm{x}} \mathrm{Cu}_{\mathrm{x}} \mathrm{TiO}_{3}$ powders. In this work, the polymeric resin was heated in a conventional oven at $350^{\circ} \mathrm{C}$ for $4 \mathrm{~h}$ using a heating rate of $1{ }^{\circ} \mathrm{C} / \mathrm{min}$ (i.e., the pre-calcination). This resulting material was manually de-agglomerated in the agate mortar. Then, using a tubular oven under an $\mathrm{O}_{2}$ atmosphere, this material was heated at $800^{\circ} \mathrm{C}$ for $2 \mathrm{~h}$ using a heating rate of $5^{\circ} \mathrm{C} / \mathrm{min}$ (see Fig. $2(\mathrm{a}-\mathrm{d}$ )).

The $\mathrm{Ca}_{1-\mathrm{x}} \mathrm{Cu}_{\mathrm{x}} \mathrm{TiO}_{3}$ powders with $0<x<0.10 \mathrm{~mol}$ of $\mathrm{Cu}^{2+}$ ions were characterized by XRD with Rietveld refinement using a Rigaku-DMax/2500PC (Japan) with $\mathrm{Cu}-\mathrm{K} \alpha$ radiation $(\lambda=1.5406 \AA$ ). The analysis was conducted in the $2 \theta$ range from $10^{\circ}$ to $130^{\circ}$ with a scanning rate of $0.02^{\circ} / \mathrm{min}$. The Rietveld refinement was performed using the General Structure Analysis software (GSAS) program [24]. Rietveld refinement is a method in which the position and intensity of peaks in a diffraction pattern obtained from step-scanning measurements enables an approximate structural model of an actual structure to be produced [25]. Hence, refined parameters for all the samples were obtained, such as the scale factor, background, shift lattice constants, profile of half-width parameters $(u, v, w)$, isotropic thermal parameters, strain anisotropy factor, occupancy, and atomic functional positions. Furthermore, the background was corrected using a Chebyshev polynomial of the first kind. The model described by Stephens [26] was used to account for the anisotropy in the half width of the reflections. As implemented in the GSAS program, the profile peak function was modeled using a convolution of the Thompson-Cox-Hastings pseudo-Voigt function [27] with the asymmetry function described by Finger et al. [28].

Micro Raman (MR) spectra were obtained using the $488 \mathrm{~nm}$ line of a Nd:YAG laser, maintaining its maximum output power at $25 \mathrm{~mW}$ to study the structural organization at short-range. The surface areas of the $\mathrm{Ca}_{1-\mathrm{x}} \mathrm{Cu}_{\mathrm{x}} \mathrm{TiO}_{3}$ powders were evaluated by the BET method using nitrogen adsorption/desorption analysis, which was conducted on a Micromeritics ASAP 2010 surface area and porosity analyzer. The morphologies of the as-prepared $\mathrm{Ca}_{1-\mathrm{x}} \mathrm{Cu}_{\mathrm{x}} \mathrm{TiO}_{3}$ powders were thoroughly investigated using FE-SEM (JEOL, Model 7500F, JEOL Ltd. Tokyo, Japan). The UV-vis absorption spectroscopy of the as-prepared materials was performed using Cary $5 \mathrm{G}$ equipment, and the band-gap energy

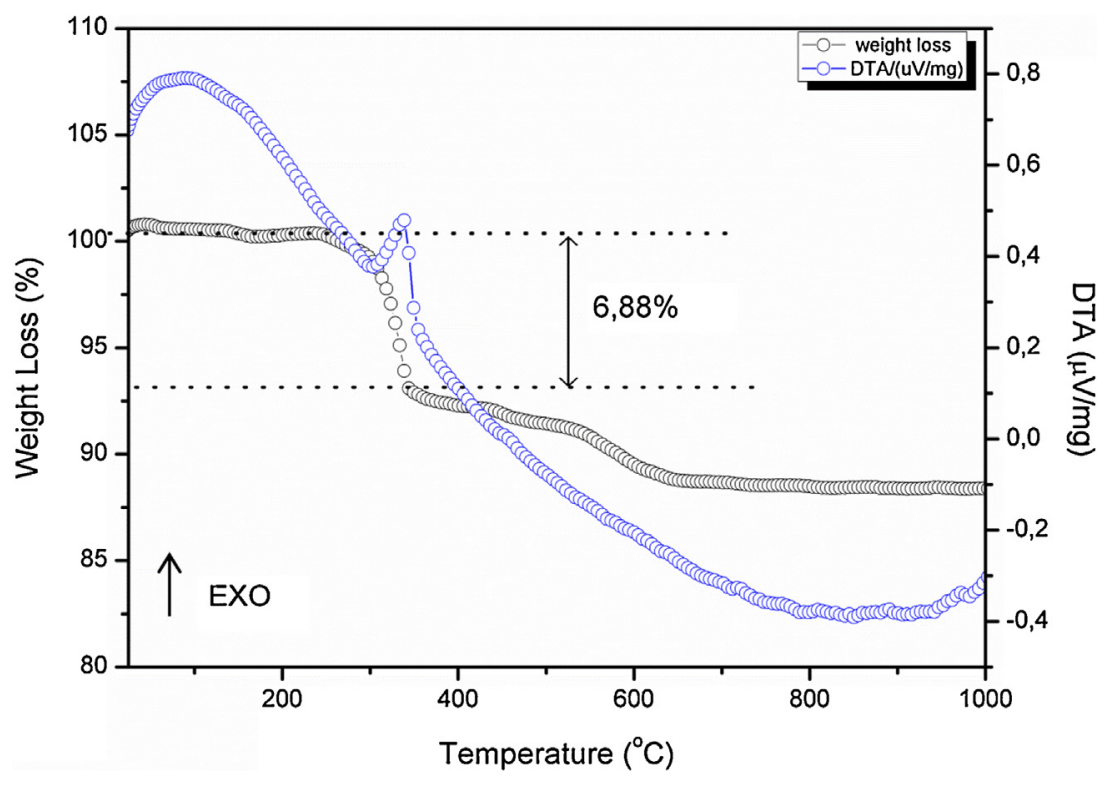

Fig. 1. TGA/DTA curves of amorphous powder obtained by the calcination of the polymeric gel. 


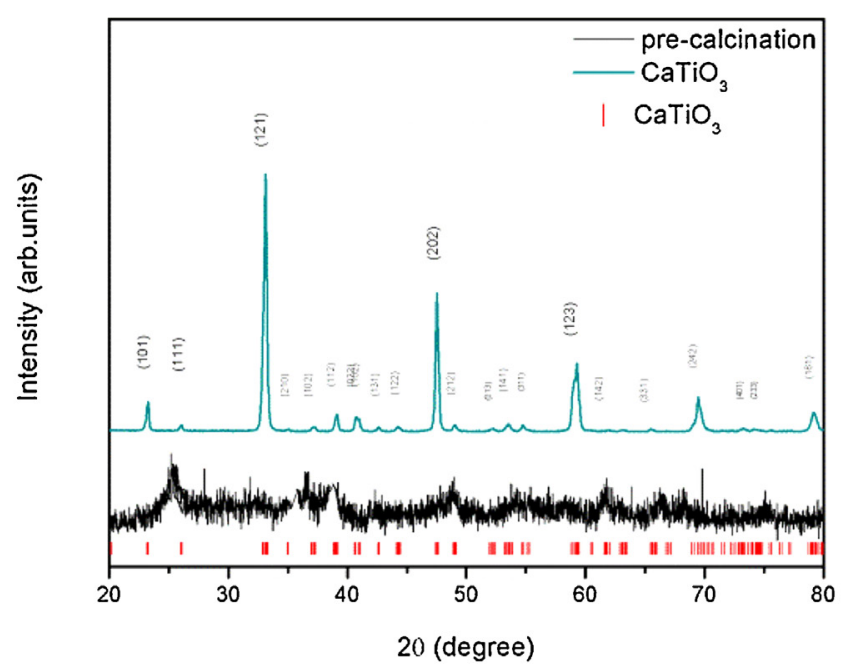

(a)

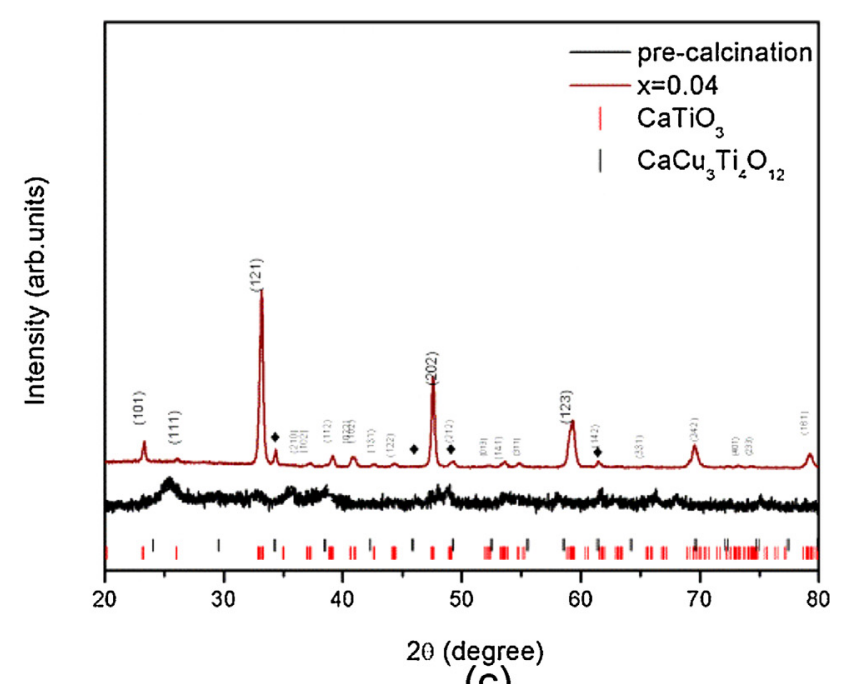

(c)

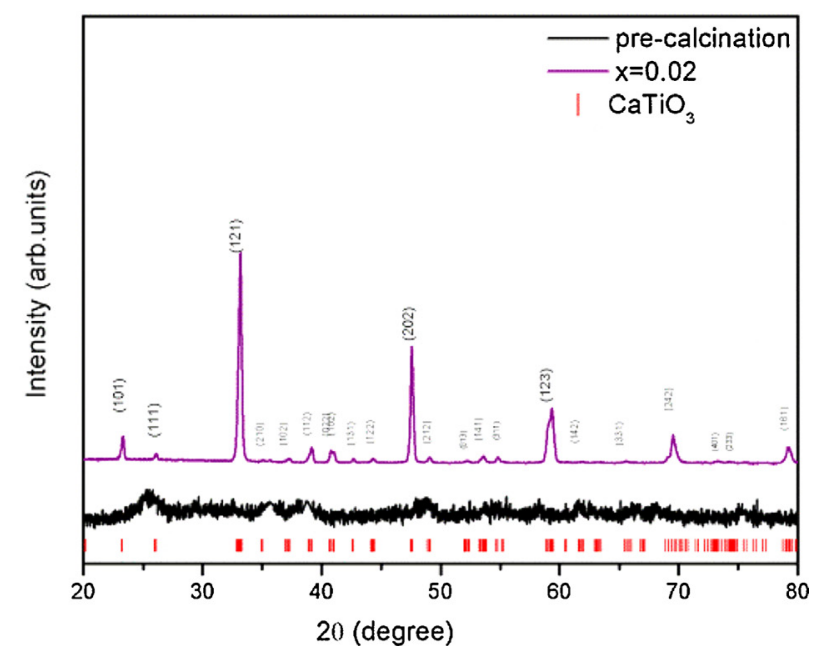

(b)

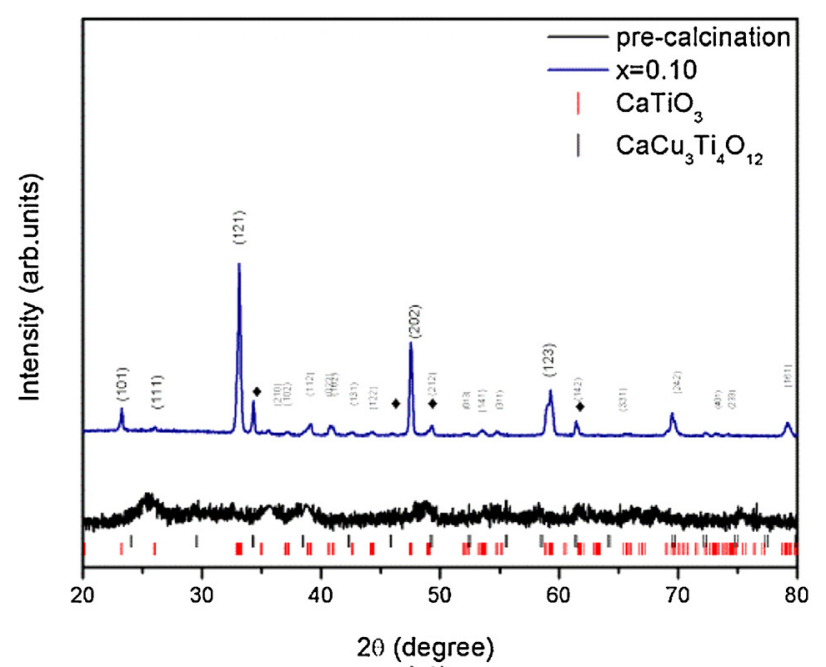

(d)

Fig. 2. (a-d) XRD patterns of $\mathrm{Ca}_{1-\mathrm{x}} \mathrm{Cu}_{\mathrm{x}} \mathrm{TiO}_{3}$ powders. Inset in (a-d) illustrates XRD patterns for the pre-calcination step.

$\left(E_{\text {gap }}\right)$ values were calculated by the Kubelka-Munk method [29]. The PL emission spectra were measured with a 139 Thermal JarrelAsh Monospec 27 monochromator and a Hamamatsu R446 photomultiplier. A krypton ion laser (Coherent Innova) with an exciting wavelength of $350 \mathrm{~nm}$ was used, maintaining a nominal output power of $200 \mathrm{~mW}$. All the measurements were performed at room temperature.

\section{Results and discussion}

The crystalline structure of the as-prepared $\mathrm{Ca}_{1-\mathrm{x}} \mathrm{Cu}_{\mathrm{x}} \mathrm{TiO}_{3}$ powders were evaluated by XRD with Rietveld refinement analysis and MR spectroscopy. Fig. 2 (a-d) shows the XRD patterns of the $\mathrm{Ca}_{1-\mathrm{x}} \mathrm{Cu}_{\mathrm{x}} \mathrm{TiO}_{3}$ powders, revealing a polycrystalline nature at longrange. An analysis of these results indicated that all the diffraction peaks were perfectly indexed to the CTO orthorhombic structure with a space group of Pbnm, in accordance with the Inorganic Crystal Structure Database (ICSD) card number 74-212. For $x>0.02$ compositions, a CCTO cubic secondary phase with a space group of $I m-3$ was identified in addition to the CTO phase. The secondary phase was indexed according to ICSD card number 95-714. This suggests that the presence of the CCTO phase was owed to the limited atomic diffusion of the $\mathrm{Ca}, \mathrm{Ti}$, and $\mathrm{Cu}$ atoms, which is promoted by the extended heat treatments used to eliminate the organic material. Furthermore, these findings suggest that the amount of precipitated CCTO phase increased as the $\mathrm{Cu}^{2+}$ ion concentration increased.

The Rietveld refinement measurements of the as-prepared $\mathrm{Ca}_{1-\mathrm{x}} \mathrm{Cu}_{\mathrm{x}} \mathrm{TiO}_{3}$ powders were used to elucidate the structural changes and to determine the percentage of the second phase, as shown in Fig. 3 and Table 1. As shown in Fig. 3 (a-d), the Rietveld refinement results showed a good relationship between the observed XRD patterns and the theoretical ones. The solubility limit was estimated as $\sim 0.02 \mathrm{~mol}$ for the CTO orthorhombic structure. In these analyses, the determined percentages of the secondary phase in $x=0.04$ and $x=0.10$ systems were $4.34 \mathrm{wt} . \%$ and 9.80 wt.\%, respectively, indicating that all the $\mathrm{Cu}$ atoms are crystallized in a CCTO secondary phase.

In CTO unit cell, the Ca atoms are coordinated to twelve $\mathrm{O}$ atoms that form dodecahedral $\left[\mathrm{CaO}_{12}\right]$ clusters, while the Ti atoms are coordinated to six $\mathrm{O}$ atoms that form octahedral $\left[\mathrm{TiO}_{6}\right]$ clusters. In this structure, the adjacent $\left[\mathrm{TiO}_{6}\right]$ clusters are displaced from its symmetric center. For $\mathrm{Ca}_{1-\mathrm{x}} \mathrm{Cu}_{\mathrm{x}} \mathrm{TiO}_{3}$ powders, this effect can be noted by the small variation of approximately $156-158^{\circ}$ between $\left[\mathrm{TiO}_{6}\right]-\alpha-\left[\mathrm{TiO}_{6}\right]$ clusters. This behavior can be attributed to the replacement by the $\mathrm{Ca}^{2+}$ ions to $\mathrm{Cu}^{2+}$ ions into A-site of the perovskite structure, i.e., due to its polarization effect on $\left[\mathrm{CaO}_{12}\right]$ e $\left[\mathrm{TiO}_{6}\right]$ clusters in the host lattice, which is able to create distortions 


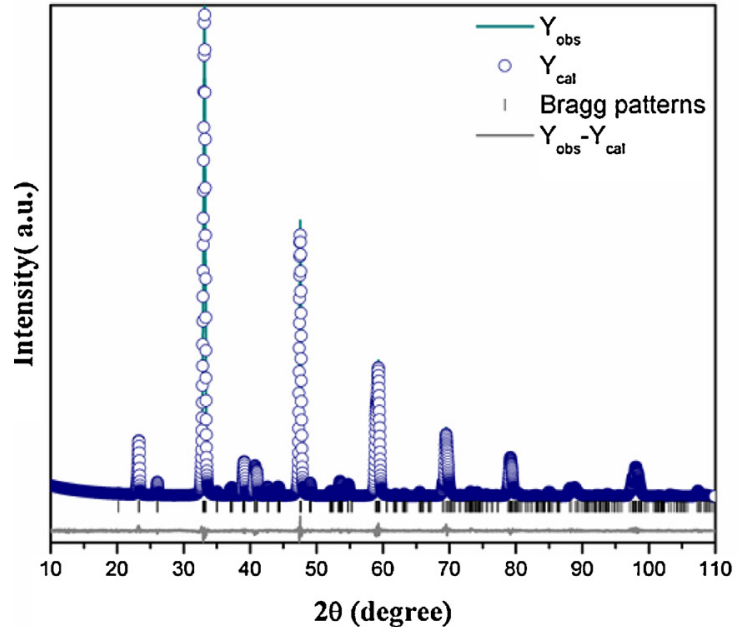

(a)

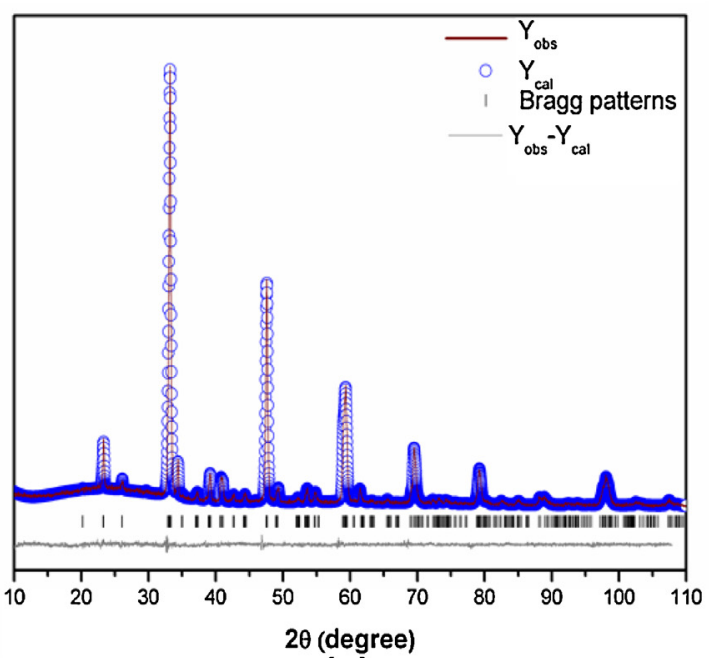

(c)

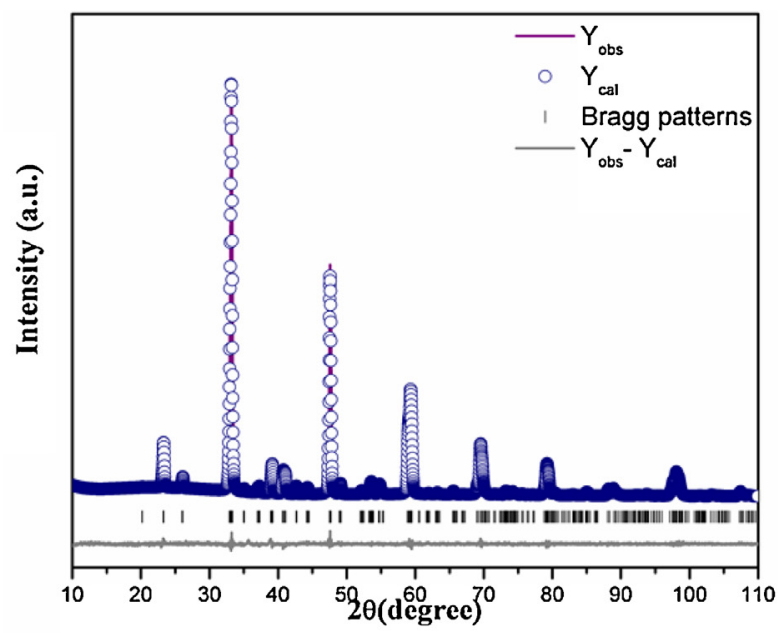

(b)

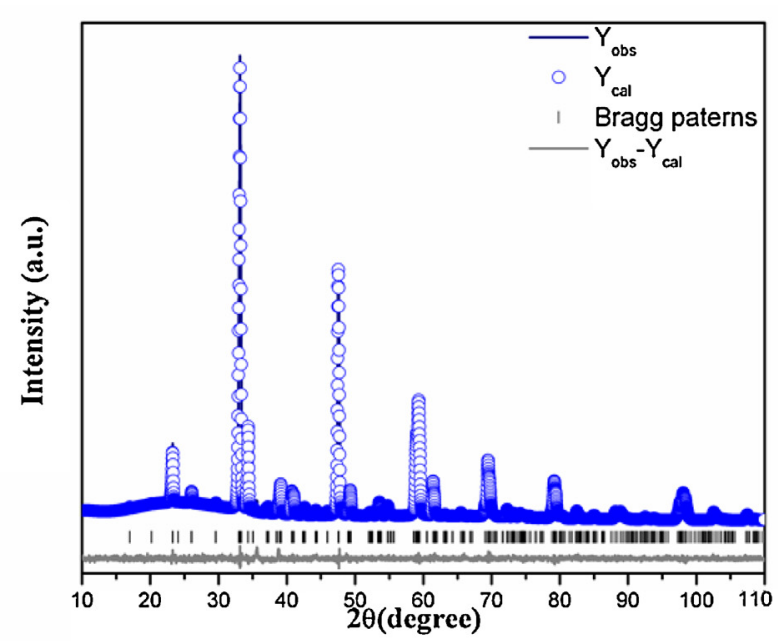

(d)

Fig. 3. Rietveld refinements of the XRD patterns of as-prepared $\mathrm{Ca}_{1-\mathrm{x}} \mathrm{Cu}_{\mathrm{x}} \mathrm{TiO}_{3}$ powders: (a) CTO, (b) $x=0.02$, (c) $x=0.04$, and (d) $x=0.10$.

and strains in $\mathrm{Ca}_{1-\mathrm{x}} \mathrm{Cu}_{\mathrm{x}} \mathrm{TiO}_{3}$ powders and also have strong an influence on its optical properties [30]. However, it can be noted that the lattice parameters and unit cell volumes obtained through the XRD refinement are very close to those published in the literature for the CTO materials [30-32]. Moreover, changes in the crystallization, heating rates, heat-treatment temperature, processing time, or crystal growth process can influence the structural distortion degree of the octahedral $\mathrm{TiO}_{6}$ clusters within $\mathrm{CTO}$ matrix [33,34].

Most notably, there were no other significant changes in the lattice parameter values with the introduction of $\mathrm{Cu}^{2+}$ ions into the A sites of the $\mathrm{Ca}_{1-x} \mathrm{Cu}_{x} \mathrm{TiO}_{3}$ powders. This may be associated with the heat treatment conditions used to obtain the $\mathrm{Ca}_{1-x} \mathrm{Cu}_{x} \mathrm{TiO}_{3}$ powders. In the polymeric precursor method, the amorphous powder has been subjected to a heat treatment in a conventional oven. During this process, the energy is slowly transferred from the surface of the powder to its interior, promoting the growth of a CTO crystalline structure with a greater degree of structural organization. Moreover, it should be noted that $\mathrm{Ca}^{2+}$ and $\mathrm{Cu}^{2+}$ possess similar ionic radii $\left(\mathrm{Cu}^{2+}=0.960 \AA\right.$ and $\left.\mathrm{Ca}^{2+}=0.969 \AA\right)$. This corresponds with the lack of variation in the lattice parameters and the cell volume of the copper-doped CTO, as shown in Table 1. Furthermore, the peaks (212), (142) observed in the XRD patterns of CTO phase, also should be attribute to CCTO phase

Table 1

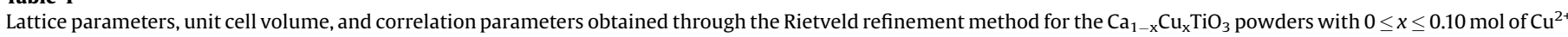
ions prepared by polymeric precursor method.

\begin{tabular}{|c|c|c|c|c|c|c|c|c|}
\hline & \multicolumn{3}{|c|}{ LatticeParameters } & \multirow[t]{2}{*}{$V\left(\AA^{3}\right)$} & \multirow[t]{2}{*}{$\alpha[\mathrm{Ti}-\mathrm{O}-\mathrm{Ti}]$} & \multirow[t]{2}{*}{$\mathrm{R}_{\text {Bragg }}(\%)$} & \multirow[t]{2}{*}{ Rwp(\%) } & \multirow[t]{2}{*}{$\chi^{2}$} \\
\hline & $\mathrm{a}(\AA)$ & $\mathrm{b}(\AA)$ & $c(\AA)$ & & & & & \\
\hline СTO & $5.3864(8)$ & $5.4374(8)$ & $7.6464(11)$ & $223.9(6)$ & $156.3^{\circ}$ & 3.14 & 8.44 & 1.313 \\
\hline$x=0.02$ & $5.3863(9)$ & $5.4382(10)$ & $7.6457(13)$ & $223.9(7)$ & $157.2^{\circ}$ & 3.46 & 6.89 & 1.33 \\
\hline$x=0.04$ & $5.3868(16)$ & $5.4374(18)$ & $7.6464(23)$ & $223.9(11)$ & $157.8^{\circ}$ & 3.57 & 5.96 & 1.27 \\
\hline$x=0.10$ & $5.3861(12)$ & $5.4369(13)$ & $7.6449(17)$ & $223.8(8)$ & $157.9^{\circ}$ & 4.39 & 5.39 & 1.34 \\
\hline
\end{tabular}


simultaneously, and as a consequence of the increase in $\mathrm{Cu}$ composition is observed a large increase in the relative intensity of these peaks, which is in good agreement with the Rietveld refinement results.

For $x \geq 0.02$ compositions, we observed the formation of a CCTO/CTO polycrystalline system [11]. In the CCTO structure, the $\mathrm{Cu}$ atoms are coordinated with four oxygen atoms of the squareplanar $\left[\mathrm{CuO}_{4}\right]$ clusters. Moreover, the distortion of the $\left[\mathrm{TiO}_{6}\right]$ clusters in the ССТО matrix, owed to changes in the $\mathrm{Cu}-\mathrm{O}$ bond length, could increase the number of $\left[\mathrm{TiO}_{5} \mathrm{~V}_{\mathrm{O}}{ }^{\bullet}\right]-\left[\mathrm{TiO}_{6}\right]$ clusters in the structure. The refinement results reveal a square planar distorted octahedral $\mathrm{Cu}^{2+}$ complexes clusters, as a consequence of Jahn-Teller effects [35]. In this case, the conductivity of CCTO would be owed to charge transference from $\left[\mathrm{TiO}_{5} \mathrm{~V}_{0}{ }^{\bullet}\right]$ to $\left[\mathrm{CuO}_{4}\right]^{\prime}$, $\left[\mathrm{TiO}_{5} \mathrm{~V}_{\mathrm{o}}{ }^{x}\right]$ to $\left[\mathrm{CuO}_{4}\right]^{x}$, or $\left[\mathrm{CuO}_{4}\right]^{\prime}$ to $\left[\mathrm{CuO}_{4}\right]^{x}$. Moreover, this process leads to the production of a $\mathrm{Cu}^{+}$species $\left(\left[\mathrm{CuO}_{4}\right]^{\prime}\right)$ in the lattice [3641]. Thus, MR spectroscopy can be used to determine the level of structural defects or asymmetry-symmetry in the $\mathrm{Ca}_{1-\mathrm{x}} \mathrm{Cu}_{\mathrm{x}} \mathrm{TiO}_{3}$ systems.

Fig. 4 shows the MR spectra of $\mathrm{Ca}_{1-\mathrm{x}} \mathrm{Cu}_{\mathrm{x}} \mathrm{TiO}_{3}$ powders, confirming the structural order at short-range. The structural behavior of the CTO powders resulted in nine Raman-active modes at $156,180,224,246,285,335,470,491$, and $631 \mathrm{~cm}^{-1}$, which are assigned to the orthorhombic structure of the CTO. In particular, the peaks located at around 156, 180, 224, 246, 285, and $335 \mathrm{~cm}^{-1}$ are associated with the $[\mathrm{O}-\mathrm{Ti}-\mathrm{O}]$ bending vibration modes, while the peaks at 470 and $491 \mathrm{~cm}^{-1}$ are assigned to distortions in the $\left[\mathrm{TiO}_{6}\right]$ octahedral clusters. The peak at $631 \mathrm{~cm}^{-1}$ is assigned to the [Ti-O-Ti] anti-symmetric stretching mode of the $\left[\mathrm{TiO}_{6}\right]$ octahedral clusters $[9,10]$. For the $\mathrm{Ca}_{1-\mathrm{x}} \mathrm{Cu}_{\mathrm{x}} \mathrm{TiO}_{3}$ powders with $x=0.0$ and $x=0.02$, the horizontal arrows indicate the broadening of the $631 \mathrm{~cm}^{-1}$ Raman-active mode as a function of the $\mathrm{Cu}^{2+}$ ion concentration in the CTO lattice. In our previous work [30], significant changes in this Raman mode could be related to the symmetry breaking of the $\left[\mathrm{CaO}_{12}\right]$ clusters caused by the increase in $\mathrm{Cu}$ composition in the A-site of CTO host matrix. This suggests the existence of an asymmetric structure due to the modification of the rotational modes in the $\left[\mathrm{TiO}_{6}\right]$ octahedral clusters (see Fig. 4); specifically, a high electron density region (excess of electrons) and a low electron density region (excess of holes) are formed.

In this case, the addition of the $\mathrm{Cu}^{2+}$ ions into the CTO matrix completely changes the MR spectra at short-range. However, besides the Raman modes ascribed to the CTO orthorhombic phase for the $x=0.04$ and $x=0.10$ systems, Raman-active modes were also

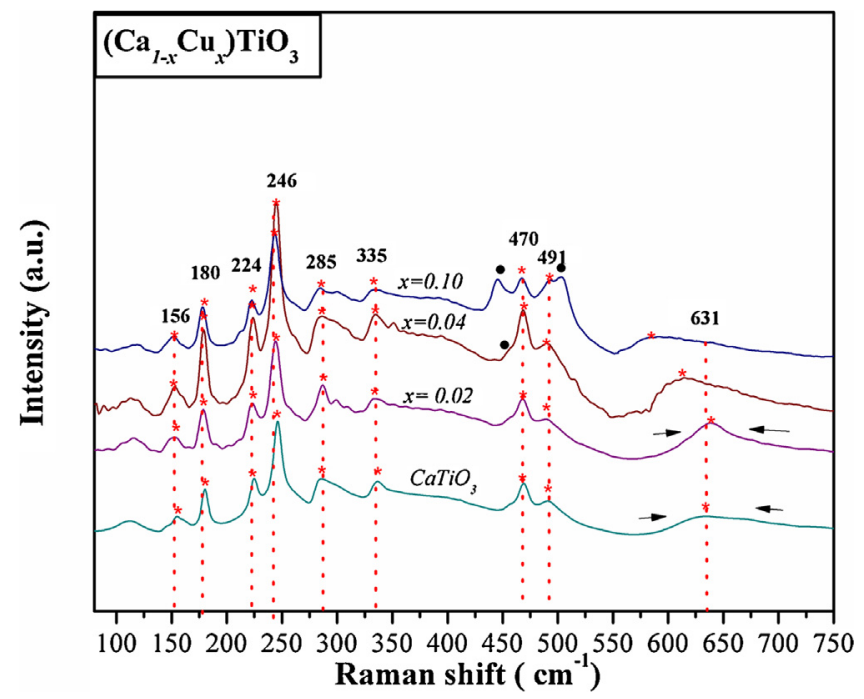

Fig. 4. MR spectra of as-prepared $\mathrm{Ca}_{1-\mathrm{x}} \mathrm{Cu}_{\mathrm{x}} \mathrm{TiO}_{3}$ powders. verified at $447 \mathrm{~cm}^{-1}\left({ }^{\bullet}\right)$ and $503 \mathrm{~cm}^{-1}(\bullet)$, which were ascribed to the rotation-like modes of the $\left[\mathrm{TiO}_{6}\right]$ linkages related to the CCTO secondary phase [42-44]. Moreover, the Raman mode at $503 \mathrm{~cm}^{-1}$ was only observed for the $x=0.10$ composition. We consider that the addition of the $\mathrm{Cu}$ atoms to the $\mathrm{Ca}_{1-\mathrm{x}} \mathrm{Cu}_{\mathrm{x}} \mathrm{TiO}_{3}$ powders ( $x=0.04$ and $x=0.10$ ) causes changes in the structural polarization of the CCTO phase. This can be attributed to structural defects (oxygen vacancies and/or distortions) owed to the different bond lengths of the $\mathrm{Cu}-\mathrm{O}$ linkages $[11,30,33]$. This behavior can be indicative of a higher $\mathrm{Ca}^{2+} / \mathrm{Cu}^{2+}$ ratio, and thus depends on the spin orientation. This appears as the secondary phase in the $\mathrm{Ca}_{1-x} \mathrm{CuxTiO3}$ samples, which is owed to the structural rearrangement from a lower-symmetry CTO orthorhombic system to a higher-symmetry CCTO cubic system. This confirms the formation of a polycrystalline system, and correlates with the Rietveld data. Therefore, the phase transformation and cluster rotation induce depolarization via the replacement of the $\mathrm{Ca}^{2+}$ ions by the $\mathrm{Cu}^{2+}$ ions.

Fig. 5 shows the FE-SEM micrographs of the as-prepared $\mathrm{Ca}_{1-x} \mathrm{Cu}_{x} \mathrm{TiO}_{3}$ powders. The inset in Fig. 5 shows the specific surface area $(\mathrm{S})$ values of the $\mathrm{Ca}_{1-x} \mathrm{Cu}_{x} \mathrm{TiO}_{3}$ powders. By analyzing the obtained results, as shown in Fig. 5, it can be determined that the $\mathrm{Ca}_{1-x} \mathrm{Cu}_{x} \mathrm{TiO}_{3}$ powders prepared by the polymeric precursor method consist of aggregated, irregular, and lamellar particles, which explains the low surface area values obtained for these systems. As can be seen in Fig. 5(a), there is little contact between the particles in the CTO powder. In this sample, the particles are less reactive (surface area of $3.61 \mathrm{~m}^{2} / \mathrm{g}$ ), and will not have sufficient energy to initiate the sintering process (neck forming); thus, the particles are merely aggregated.

When the $\mathrm{Cu}^{2+}$ concentration is increased from $x=0$ to 0.02 (see Fig. 5(b) and (c)), the bonding between the particles is enhanced because the surface area of these particles is increased from 3.61 to $3.75 \mathrm{~m}^{2} \mathrm{~g}^{-1}$, respectively. Subsequently, during the heat treatment, contact between the particles will be maintained by van der Waals forces. Sintering is initiated between the contacting particles (neck forming) and consequently large aggregates will form [45]. Moreover, as the $\mathrm{Cu}^{2+}$ concentration is increased above 0.02 , the particles become more reactive, and larger agglomerates can be observed. In general, the FE-SEM micrographs reveal that the addition of $\mathrm{Cu}^{2+}$ ions promotes the sintering process at lower temperatures, and also results in structural changes and the relaxation of the material.

Fig. 6 displays the UV-vis spectra of the as-prepared $\mathrm{Ca}_{1-\mathrm{x}} \mathrm{Cu}_{\mathrm{x}} \mathrm{TiO}_{3}$ powders. According to previous studies $[10,46]$, both the CTO and CCTO exhibit an optical absorption spectrum governed by direct electronic transitions. For the $\mathrm{Ca}_{1-\mathrm{x}} \mathrm{Cu}_{\mathrm{x}} \mathrm{TiO}_{3}$ powders, the UV-vis absorption measurements showed $E_{\text {gap }}$ values varying between 3.51 and $2.10 \mathrm{eV}$, which is associated with specific structural disordering of the lattice [10-12].

Therefore, this behavior can be associated with the formation of acceptor and donor levels between the conduction and valence bands that may have been introduced by the oxygen vacancies of the particles, which are in three different charge states (i.e., $V_{O}{ }^{x}$, $\mathrm{V}_{\mathrm{O}}$, and $\mathrm{V}_{\mathrm{O}}{ }^{\bullet \bullet}$ ). Two different band-gap values were determined for both of the $\mathrm{Ca}_{1-\mathrm{x}} \mathrm{Cu}_{\mathrm{x}} \mathrm{TiO}_{3}(\mathrm{x}=0.04$ and $\mathrm{x}=0.10)$ powders with excess $\mathrm{Cu}$ atoms (see Fig. 6). These values are associated with the CCTO cubic phase (2.45 eV and $2.05 \mathrm{eV}$ ) and the CTO orthorhombic phase ( $3.2 \mathrm{eV}$ and $2.28 \mathrm{eV}$ ). This behavior suggests that a low concentration of energy states exists within the valence and conduction bands, which can be ascribed to the increased $\mathrm{Cu}$ content within the host matrix. This plays an important role in the optical transitions of such systems. This stoichiometric change leads to a greater contribution from the $3 \mathrm{~d}$ orbital states of the $\mathrm{Cu}$ atoms in the CCTO secondary phase and a lower contribution from the Ti $3 d$ orbital states of the CTO phase $[47,48]$. So in principle, the 


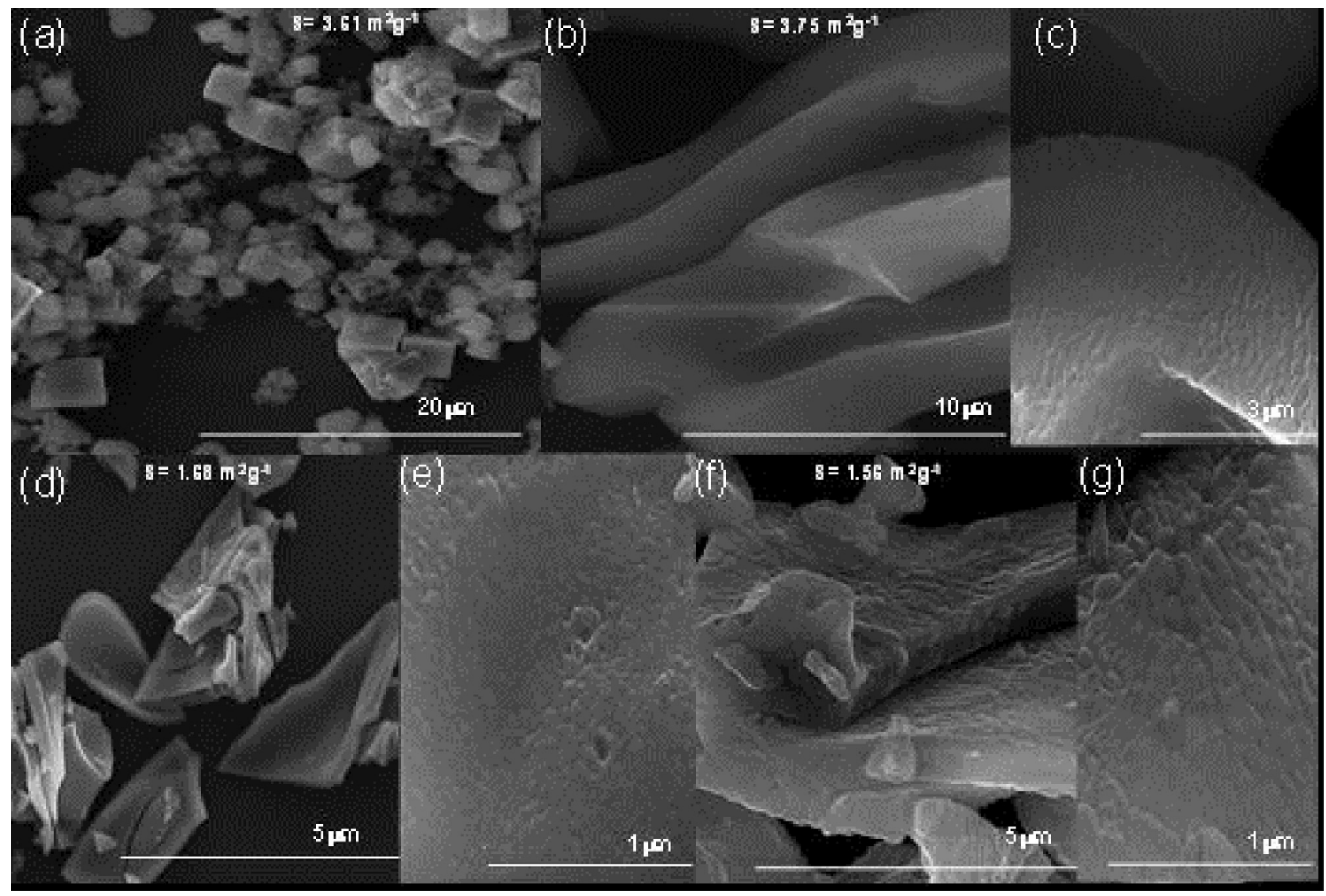

Fig. 5. FE-SEM images of CaTiO3(a), $x=0.02(\mathrm{~b} ; \mathrm{c}), x=0.04(\mathrm{~d} ; \mathrm{e})$, and $x=0.10(\mathrm{f}, \mathrm{g})$ powders prepared by the polymeric precursor method.

cluster-like elucidation have played a significant role on the understanding of PL performance is supported and strengthened by different extrinsic (at surface) and intrinsic (at bulk) defect level distributions, which are responsible for tunable the optical behavior in such systems. The defect structure and density variation surface and/or bulk might be responsible for the different PL behavior of CCTO and CTO. Effective separation (electron/hole) requires the presence of a cluster-to-cluster transfer process of electrons or holes from $\left[\mathrm{CaO}_{12}\right]_{\mathrm{o} / \mathrm{d}}$ or $\left[\mathrm{CuO}_{12}\right]_{\mathrm{o} / \mathrm{d}}$ or $\left[\mathrm{TiO}_{6}\right]_{\mathrm{o} / \mathrm{d}}$, where $\mathrm{o}=$ ordered and $\mathrm{d}=$ disordered. One way to boost PL efficiency is to exchange ordered complex clusters to disordered complex clusters.

PL measurements were performed to elucidate the influence of the various $\mathrm{Cu}$ atomic concentrations on the optical properties of the $\mathrm{Ca}_{1-\mathrm{x}} \mathrm{Cu}_{\mathrm{x}} \mathrm{TiO}_{3}$ powders. This is a very simple, convenient method for the analysis of structural defects at medium-range [4951]. Fig. 7 shows the PL emission spectra of the as-prepared $\mathrm{Ca}_{1-\mathrm{x}} \mathrm{Cu}_{\mathrm{x}} \mathrm{TiO}_{3}$ powders. Several PL emission peaks can be observed for the $\mathrm{Ca}_{1-\mathrm{x}} \mathrm{Cu}_{\mathrm{x}} \mathrm{TiO}_{3}$ powders, which exhibit typical broad-band behavior. Specifically, the relaxations involve several energy states within the band gap, which are in accordance with the optically measured gap. In particular, the individual contribution of each deconvoluted PL profile was obtained using the Voigt function of the PL emission spectra, and analyzed using the PeakFit program (version 4.05) [52]. The peak positions and corresponding areas, shown in Fig. 7, were included in the analysis.

We compare the optical behavior of the as-prepared $\mathrm{Ca}_{1-x} \mathrm{Cu}_{x} \mathrm{TiO}_{3}$ powders, which is a crucial step in order to revealing its potential applications. The $\mathrm{Ca}_{1-x} \mathrm{Cu}_{x} \mathrm{TiO}_{3}$ powders $(x=0.02$ and 0.04 ) presented six components; one component was situated at the violet region (390-418 nm), blue region ( $460-490 \mathrm{~nm}$ ), orange region $(617 \mathrm{~nm})$, and red region $(670 \mathrm{~nm})$, respectively, and two were situated at the green region $(500-565 \mathrm{~nm})$. The CTO and $x=0.10$ samples presented just two components, one at the blue region and one at the orange or red region. As can be seen, CTO system presented a PL emission mainly centered at the blue region (54.05\%), which is associated to a higher concentration of deep defects. As the $\mathrm{Cu}^{2+}$ concentration was increased to $x=0.02$, the area percentage of the orange component decreased to $1.9 \%$. Moreover, it was possible to observed a red component situated at $670 \mathrm{~nm}(2.2 \%)$. The $x=0.04$ composition presented a decrease in the area percentage of the blue (39\%) and green (15\%) components, while an increase in the area percentage of the orange (17\%) and red (7\%) components was observed. This behavior is also accompanied by the displacement of the PL emission to a higher wavelength. Finally, the PL emission of the $x=0.10$ composition was situated in just the blue region $(460 \mathrm{~nm})$. From these results, it can be determined that the increased $\mathrm{Cu}^{2+}$ concentration is responsible for promoting a reduction in the structural polarization of the $\mathrm{Ca}_{1-x} \mathrm{Cu}_{x} \mathrm{TiO}_{3}$ powders. This polarization favors the elimination of deep defects and promotes a redistribution of the intermediary states in the optical band gap. This fact suggests that the PL behavior of the $\mathrm{Ca}_{1-x} \mathrm{Cu}_{x} \mathrm{TiO}_{3}$ powders is directly influenced by the structural disorders that yield discrete levels in the forbidden band gap, which were confirmed by the UV-vis measurements (see Fig. 6). Therefore, the analysis of the PL data of the as-prepared $\mathrm{Ca}_{1-x} \mathrm{Cu}_{x} \mathrm{TiO}_{3}$ powders suggest that such materials are promising to fabrication of visible lighting lasers devices in the blue, green and red regions of the electromagnetic spectrum, i.e., depending on the Cu composition in the host matrix.

In previous studies [30], using as a strategy of synthesis the microwave-assisted hydrothermal method, in particular, the PL profile reported for the $\mathrm{Cu}$-doped CTO powders with $\mathrm{x}=0.02$ is subtly different from the one in this study. In general, the optical behavior is strongly dependent on the synthetic methods which 

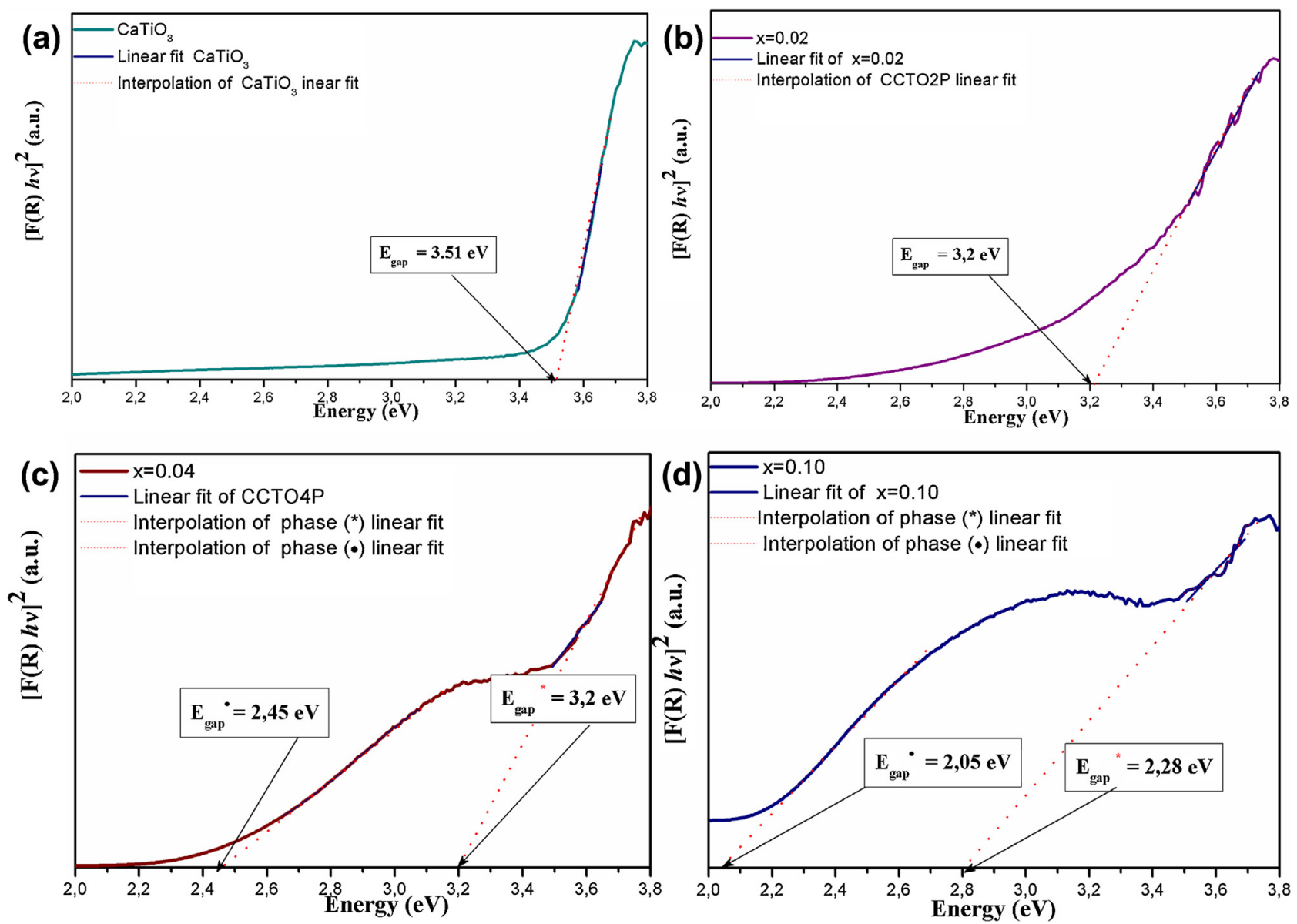

Fig. 6. UV-vis absorbance spectra of as-prepared $\mathrm{Ca}_{1-\mathrm{x}} \mathrm{Cu}_{\mathrm{x}} \mathrm{TiO}_{3}$ powders: (a) CTO, (b) $x=0.02$, (c) $x=0.04$, and (d) $x=0.10$.

provide a different structural organization level for such materials, i.e., especially at the medium range. To further clarify the PL mechanism based on structural changes induced by the dopants in the host matrix, the formation of oxygen vacancies (i.e., $\mathrm{V}_{\mathrm{O}}{ }^{\mathrm{x}}, \mathrm{V}_{\mathrm{O}}{ }^{\bullet}$, and $V_{O} \bullet$ ) has a crucial role in the elucidation of this microscopically observed behavior. The oxygen vacancies within the disordered structure may provide a possible explanation for the changes observed in the PL emission of the as-prepared $\mathrm{Ca}_{1-x} \mathrm{Cu}_{x} \mathrm{TiO}_{3}$ powders. Based on the structural order-disorder effects, we used the Kröger-Vink notation to explain and represent the oxygen vacancy formation (i.e., $\mathrm{V}_{\mathrm{O}}{ }^{\mathrm{x}}, \mathrm{V}_{\mathrm{O}}{ }^{\bullet}$, and $\mathrm{V}_{\mathrm{O}}{ }^{\bullet}$ ) in the $\mathrm{Ca}_{1-x} \mathrm{Cu}_{x} \mathrm{TiO}_{3}$ systems, which are summarized in the following equations:

$\left[\mathrm{TiO}_{6}\right]^{x}+\left[\mathrm{TiO}_{5} \mathrm{~V}_{\mathrm{o}}{ }^{x}\right] \rightarrow\left[\mathrm{TiO}_{6}\right]^{\prime}+\left[\mathrm{TiO}_{5} \mathrm{~V}_{\mathrm{o}}{ }^{\bullet}\right]$

$$
\left[\mathrm{TiO}_{6}\right]^{x}+\left[\mathrm{TiO}_{5} \mathrm{~V}_{\mathrm{o}}^{\bullet}\right] \rightarrow\left[\mathrm{TiO}_{6}\right]^{\prime}+\left[\mathrm{TiO}_{5} \mathrm{~V}_{\mathrm{o}}^{\bullet}\right]
$$

Here, $\left[\mathrm{TiO}_{6}\right]^{\prime}$ is a donor, $\left[\mathrm{TiO}_{5} \mathrm{~V}_{\mathrm{O}}^{*}\right]$ is a donor-acceptor, and $\left[\mathrm{TiO}_{5} \mathrm{~V}_{\mathrm{O}}\right]$ is an acceptor. This model can be extended for the lattice modifiers; in this case, the charge will transfer from $\left[\mathrm{TiO}_{6}\right]^{\prime}$ to $\left[\mathrm{CuO}_{12}\right]^{x}$, or from $\left[\mathrm{CuO}_{11} \mathrm{~V}_{\mathrm{O}}^{\mathrm{x}}\right]^{x}$ to $\left[\mathrm{CuO}_{12}\right]^{\prime}$.

$\left[\mathrm{CuO}_{12}\right]^{x}+\left[\mathrm{TiO}_{6}\right]^{\prime} \rightarrow\left[\mathrm{CuO}_{12}\right]^{\prime}+\left[\mathrm{TiO}_{6}\right]^{x}$

$\left[\mathrm{CaO}_{12}\right]^{x}+\left[\mathrm{CaO}_{11} \mathrm{~V}_{\mathrm{o}}{ }^{x}\right] \rightarrow\left[\mathrm{CaO}_{12}\right]^{\prime}+\left[\mathrm{CaO}_{11} \mathrm{~V}_{\mathrm{o}}{ }^{\bullet}\right]$

$\left[\mathrm{CaO}_{12}\right]^{x}+\left[\mathrm{CaO}_{11} \mathrm{~V}_{\mathrm{o}}^{\bullet}\right] \rightarrow\left[\mathrm{CaO}_{12}\right]^{\prime}+\left[\mathrm{CaO}_{11} \mathrm{~V}_{\mathrm{o}}^{\bullet \bullet}\right]$
$\left[\mathrm{CuO}_{12}\right]^{x}+\left[\mathrm{CaO}_{12}\right]^{\prime} \rightarrow\left[\mathrm{CuO}_{12}\right]^{\prime}+\left[\mathrm{CaO}_{12}\right]^{x}$

Following the above logic, the following equations can summarize the charge transfer among the clusters for the CCTO secondary phase:

$\left[\mathrm{CuO}_{4}\right]^{x}+\left[\mathrm{TiO}_{6}\right]^{\prime} \rightarrow\left[\mathrm{CuO}_{4}\right]^{\prime}+\left[\mathrm{TiO}_{6}\right]^{x}$

$\left[\mathrm{CuO}_{4}\right]^{x}+\left[\mathrm{CaO}_{12}\right]^{\prime} \rightarrow\left[\mathrm{CuO}_{4}\right]^{\prime}+\left[\mathrm{CaO}_{12}\right]^{\mathrm{x}}$

$\left[\mathrm{CuO}_{4}\right]^{\prime} \stackrel{e^{\prime}}{\rightarrow}\left[\mathrm{CuO}_{4}\right]^{x}$ where, $\mathrm{Cu}^{\mathrm{II}}$ and $\mathrm{Cu}^{\mathrm{I}}$

In this case, the charge will transfer from $\left[\mathrm{TiO}_{6}\right]^{\prime}$ to $\left[\mathrm{CuO}_{4}\right]^{x}$ or from $\left[\mathrm{CuO}_{11} \mathrm{~V}_{\mathrm{O}}^{x}\right]^{x}$ to $\left[\mathrm{CuO}_{12}\right]^{\prime}$. An analysis of the complex clusters based on the Kröger-Vink notation for these systems revealed that chemical substitution promotes the formation of oxygen vacancies and can explain, in principle, the higher densification observed in the СТO phase and hence are consistent with our previous reported [11], in which the analysis of the X-ray absorption near edge structure (XANES) spectroscopy that reveals different coordination environments for these materials.

The intentional structural changes generated by the compositional modulation of the system can be reasonably understood by equations 1-9, which summarize the modification of the local matrix responsible for the creation of new luminescent centers in such materials. For these systems, the charge transfer that occurs during the formation of these species is strongly related to the structural distortions of the $\left[\mathrm{TiO}_{6}\right]-\alpha-\left[\mathrm{TiO}_{6}\right]$ clusters and the 


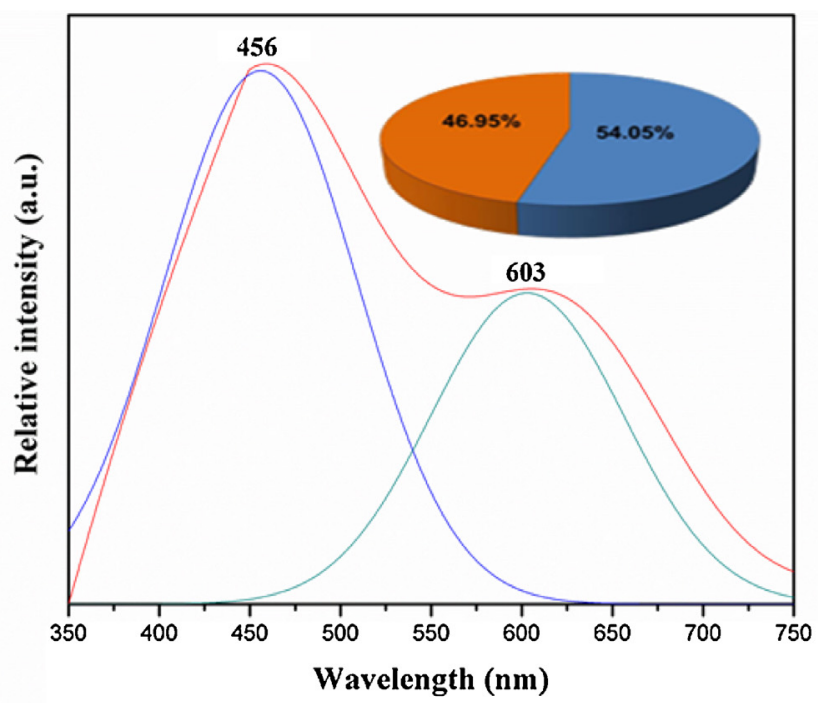

(a)

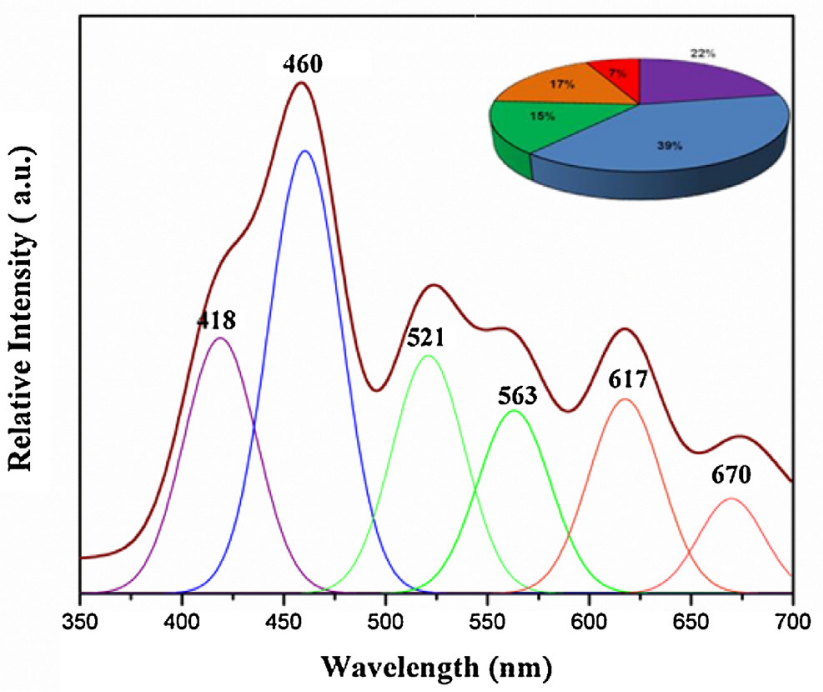

(c)

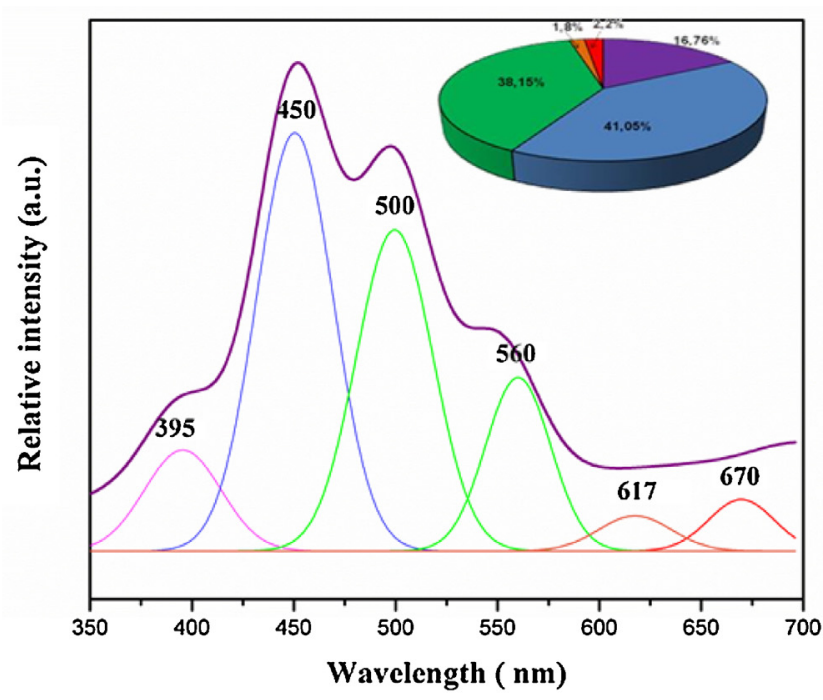

(b)

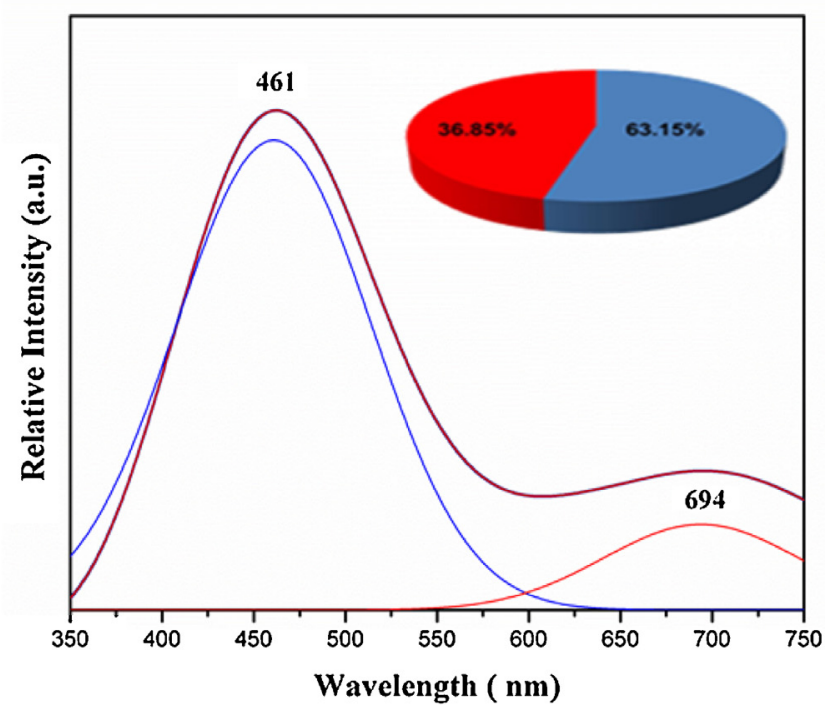

(d)

Fig. 7. Deconvolution of PL emission spectra of the as-prepared $\mathrm{Ca}_{1-\mathrm{x}} \mathrm{Cu}_{\mathrm{x}} \mathrm{TiO}_{3}$ powders: (a) CTO, (b) $x=0.02$, (c) $x=0.04$, and (d) $x=0.10$.

formation of defects inside the band gap, as discussed earlier. Thus, it is highly likely that the PL emission of the $\mathrm{Ca}_{1-x} \mathrm{Cu}_{x} \mathrm{TiO}_{3}$ powders can be explained by the identification of these key factors. Moreover, the proportion of the secondary phase also affects the PL behavior of the complex clusters in $\mathrm{Ca}_{1-x} \mathrm{Cu}_{x} \mathrm{TiO}_{3}$ systems, i.e., promotes a redistribution of the intermediary states inside the optical band gap. All these effects can generate strain and distortion in the CTO and CCTO crystalline lattice by modifying the density of structural defects. This promotes control of the PL behavior, and hence provides a rational method to analyze the effects of order-disorder on the electronic structure of these systems.

\section{Conclusions}

This work reported on the optical properties and structural control of $\mathrm{Ca}_{1-x} \mathrm{Cu}_{x} \mathrm{TiO}_{3}$ powders synthesized via the polymeric precursor method. XRD with Rietveld refinements, MR, FE-SEM,
BET, UV-vis, and PL measurements were extensively employed to investigate the relationship between the structure and properties of these complex materials based on $\mathrm{Ca}_{1-x} \mathrm{Cu}_{x} \mathrm{TiO}_{3}$ systems. The XRD and Rietveld results suggest that a CTO/CCTO polycrystalline system forms in powders with a $\mathrm{Cu}^{2+}$ ion concentration are greater than 0.02. For the powders with $\mathrm{Cu}$ concentrations of $x=0.04$ and 0.10 , the MR spectroscopy also presented a different Raman-active mode, which was ascribed to the rotation-like modes of the $\left[\mathrm{TiO}_{6}\right]$ linkages related to the CCTO phase. This can be ascribed to a structural rearrangement in the $\mathrm{Ca}_{1-x} \mathrm{Cu}_{x} \mathrm{TiO}_{3}$ samples, from a lower-symmetry CTO orthorhombic system to a higher-symmetry CCTO cubic system. These distortions (i.e., on short-, medium-, and long-range length scales) in the structural arrangement of the $\mathrm{Ca}_{1-x} \mathrm{Cu}_{x} \mathrm{TiO}_{3}$ system are responsible for the rational control of their physical and chemical properties. The optical behavior of the $\mathrm{Ca}_{1-x} \mathrm{Cu}_{x} \mathrm{TiO}_{3}$ powders are directly influenced by structural disorders that yield discrete levels in the forbidden band gap, which suggests that the samples have varying concentrations of 
deep and shallow defects. Our results demonstrate the influence of the structural changes originating from the modification of the matrix (i.e., the effect of replacing $\mathrm{Ca}^{+2}$ with $\mathrm{Cu}^{+2}$ in $\mathrm{Ca}_{1-x} \mathrm{Cu}_{x} \mathrm{TiO}_{3}$ powders), which is crucial for the future development of devices that will use these complex systems.

\section{Acknowlegments}

The authors appreciate the support of the following Brazilian research financing institutions CAPES,CNPq and FAPESP (Proc. 2009/00367-6 and Proc. 2013/14647-6)

\section{References}

[1] J. Jumpatam, B. Putasaeng, T. Yamwong, P. Thongbai, S. Maensiri, J. Eur. Ceram. Soc. 34 (2014) 2941-2950.

[2] J. Maul, A. Erba, I.M. Santos, J.R. Sambrano, R. Dovesi, J. Chem. Phys. 142 (2015) 014505.

[3] G.F. Teixeira, T.R. Wright, D.C. Manfroi, E. Longo, J.A. Varela, M.A. Zaghete, Mater. Lett. 139 (2015) 443-446.

[4] S. Thirumalairajan, K. Girija, V.R. Mastelaro, N. Ponpandian, ACS Appl Mater. Interfaces 6 (2014) 13917-13927.

[5] Y. Yamada, Y. Kanemitsu, J. Lumin. 133 (2013) 30-34.

[6] T. Kimijima, K. Kanie, M. Nakaya, A. Muramatsu, Appl. Catal. B: Environ. 144 (2014) 462-467.

[7] T. Kimijima, K. Kanie, M. Nakaya, A. Muramatsu, CrystEngComm 16 (2014) $5591-5597$.

[8] C.R. Foschini, R. Tararam, A.Z. Simões, M. Cilense, E. Longo, J.A. Varela, J. Alloys Compd. 574 (2013) 604-608.

[9] T.M. Mazzo, L.M.R. Oliveira, L.R. Macario, W. Avansi Jr., R.D.S. André, I.L.V. Rosa, J.A. Varela, E. Longo, Mater. Chem. Phys. 145 (2014) 141-150.

[10] M.L. Moreira, E.C. Paris, G.S. Nascimento, V.M. Longo, J.R. Sambrano, V.R. Mastelaro, M.I.B. Bernardi, J. Andrés, J.A. Varela, E. Longo, Acta Mater. 57 (2009) 5174-5185.

[11] L.H. Oliveira, E.C. Paris, W. Avansi, M.A. Ramirez, V.R. Mastelaro, E. Longo, J.A. Varela, X.M. Chen, J. Am. Ceram. Soc. 96 (2013) 209-217.

[12] R. Parra, R. Savu, L.A. Ramajo, M.A. Ponce, J.A. Varela, M.S. Castro, P.R. Bueno, E. Joanni, J. Solid State Chem. 183 (2010) 1209-1214.

[13] L. Ramajo, R. Parra, J.A. Varela, M.M. Reboredo, M.A. Ramírez, M.S. Castro, J. Alloys Compd. 497 (2010) 349-353.

[14] T. Sequinel, I.G. Garcia, S.M. Tebcherani, E.T. Kubaski, L.H. Oliveira, M.S. Li, E Longo, J.A. Varela, J. Alloys Compd. 583 (2014) 488-491.

[15] A.O. Turky, M.M. Rashad, Z.I. Zaki, I.A. Ibrahim, M. Bechelany, RSC Adv. 5 (2015) 18767-18772.

[16] M.M. Nakata, T.M. Mazzo, G.P. Casali, F.A. La Porta, E. Longo, Chem. Phys. Lett. 622 (2015) 9-14.

[17] F. Moura, A.C. Cabral, L.S.R. Rocha, E.C. Aguiar, A.Z. Simões, E. Longo, Ceram. Int. 42 (2016) 4837-4844.

[18] T. Wanjun, C. Donghua, Mater. Res. Bull. 44 (2009) 836-839.

[19] J. Jumpatam, B. Putasaeng, T. Yamwong, P. Thongbai, S. Maensiri, Mater. Res. Bull. 77 (2016) 178-184.

[20] C.K. Yeoh, M.F. Ahmad, Z.A. Ahmad, J. Alloys Compd. 443 (2007) 155-160.
[21] T.T. Fang, L.T. Mei, J. Am. Ceram. Soc. 90 (2007) 638-640.

[22] B. Shri Prakash, K.B.R. Varma, J. Mater. Sci. 42 (2007) 7467-7477.

[23] B. Cheng, Y.-H. Lin, H. Yang, J. Lan, C.-W. Nan, X. Xiao, J. He, J. Am. Ceram. Soc. 92 (2009) 2776-2779.

[24] A.C. Larson, R.B.V. Dreele, Los Alamos National Laboratory, in: L.A.N. Laboratory (Ed.), Los Alamos, NM, 2001, pp. 230.

[25] H. Rietveld, J. Appl. Crystallogr. 2 (1969) 65-71.

[26] P. Stephens, J. Appl. Crystallogr. 32 (1999) 281-289.

[27] P. Thompson, D.E. Cox, J.B. Hastings, J. Appl. Crystallogr. 20 (1987) 79-83.

[28] L.W. Finger, D.E. Cox, A.P. Jephcoat, J. Appl. Crystallogr. 27 (1994) 892-900.

[29] P. Kubelka, F. Munk Aussig, Für. Technol. Phys. 12 (1931) 593-601.

[30] L.H. Oliveira, A.P. de Moura, T.M. Mazzo, M.A. Ramírez, L.S. Cavalcante, S.G. Antonio, W. Avansi, V.R. Mastelaro, E. Longo, J.A. Varela, Mater. Chem. Phys. 136 (2012) 130-139.

[31] L.S. Cavalcante, V.S. Marques, J.C. Sczancoski, M.T. Escote, M.R. Joya, J.A. Varela, M.R.M.C. Santos, P.S. Pizani, E. Longo, Chem. Eng. J. 143 (2008) 299-307.

[32] R.F. Gonçalves, A.R.F. Lima, M.J. Godinho, A.P. Moura, J. Espinosa, E. Longo, A.P. A. Marques, Ceram. Int. 41 (2015) 12841-12848.

[33] V.S. Marques, L.S. Cavalcante, J.C. Sczancoski, D.P. Volanti, J.W.M. Espinosa, M.R. Joya, M.R.M.C. Santos, P.S. Pizani, J.A. Varela, E. Longo, Solid State Sci. 10 (2008) 1056-1061.

[34] E.S. Junior, F.A. La Porta, M.S. Li, J. Andrés, J.A. Varela, E. Longo, Dalton Trans. 44 (2015) 3159-3175.

[35] J.H. Clark, M.S. Dyer, R.G. Palgrave, C.P. Ireland, J.R. Darwent, J.B. Claridge, M.J. Rosseinsky, J. Am. Chem. Soc. 133 (2011) 1016-1032.

[36] D. Capsoni, M. Bini, V. Massarotti, G. Chiodelli, M.C. Mozzatic, C.B. Azzoni, J. Solid State Chem. 177 (2004) 4494-4500.

[37] B. Cheng, Y.-H. Lin, H. Yang, J. Lan, C.-W. Nan, X. Xiao, J. He, J. Am. Ceram. Soc. 92 (2009) 2776-2779.

[38] O.F. Schirmer, Ferroelectrics 303 (2004) 131-135.

[39] M.H. Whangbo, M.A. Subramanian, Chem. Mater. 18 (2006) 3257-3260.

[40] L. Wu, Y. Zhu, S. Park, S. Shapiro, G. Shirane, J. Tafto, Phys. Rev. B 71 (2005) 014118.

[41] A.F.L. Almeida, R.S.D. Oliveira, J.C. Goes, J.M. Sasaki, A.G. Souza Filho, J. Mendes Filho, A.S.B. Sombra, Mater. Sci. Eng. B 96 (2002) 275-283.

[42] N. Kolev, R.P. Bontchev, A.J. Jacobson, V.N. Popov, V.G. Hadjiev, A.P. Litvinchuk, M.N. Iliev, Phys. Rev. B 66 (2002) 132102.

[43] D. Valim, A.G. Souza Filho, P.T.C. Freire, S.B. Fagan, A.P. Ayala, J. Mendes Filho, A. F.L. Almeida, P.B.A. Fechine, A.S.B. Sombra, J. Staun Olsen, L. Gerward, Phys. Rev. B 70 (2004) 132103.

[44] R.M. German, Fundamentals of sintering, in: S.J. Schneider (Ed.), Engineered Materials Handbook: Ceramics and Glasses, ASM International, 1991.

[45] R.F. Gonçalves, M.J. Godinho, E.R. Leite, A.P. Maciel, E. Longo, J.A. Varela, J. Mater. Sci. 42 (2007) 2222-2225.

[46] S.B. Fagan, A.G. Souza Filho, A.P. Ayala, J.M. Filho, Phys. Rev. B 72 (2005) 014106.

[47] M. Matos, L. Walmsley, J. Phys.: Condens. Matter 18 (2006) 1793.

[48] J.-C. Zheng, A.I. Frenkel, L. Wu, J. Hanson, W. Ku, E.S. Božin, S.J.L. Billinge, Y. Zhu, Phys. Rev. B 81 (2010) 144203.

[49] F.M.C. Batista, F.A. La Porta, L. Gracia, E. Cerdeiras, L. Mestres, M.S. Li, N.C. Batista, J. Andrés, E. Longo, L.S. Cavalcante, J. Mol. Struct. 1081 (2015) 381-388.

[50] L.S. Cavalcante, V.M. Longo, J.C. Sczancoski, M.A.P. Almeida, A.A. Batista, J.A. Varela, M.O. Orlandi, E. Longo, M.S. Li, CrystEngComm 14 (2012) 853-868.

[51] F.A. La Porta, M.M. Ferrer, Y.V.B. de Santana, C.W. Raubach, V.M. Longo, J.R. Sambrano, E. Longo, J. Andrés, M.S. Li, J.A. Varela, J. Alloys Compd. 556 (2013) 153-159.

[52] PeakFit, version 4.05, S.S. Inc., Copyright (c) 2015. 